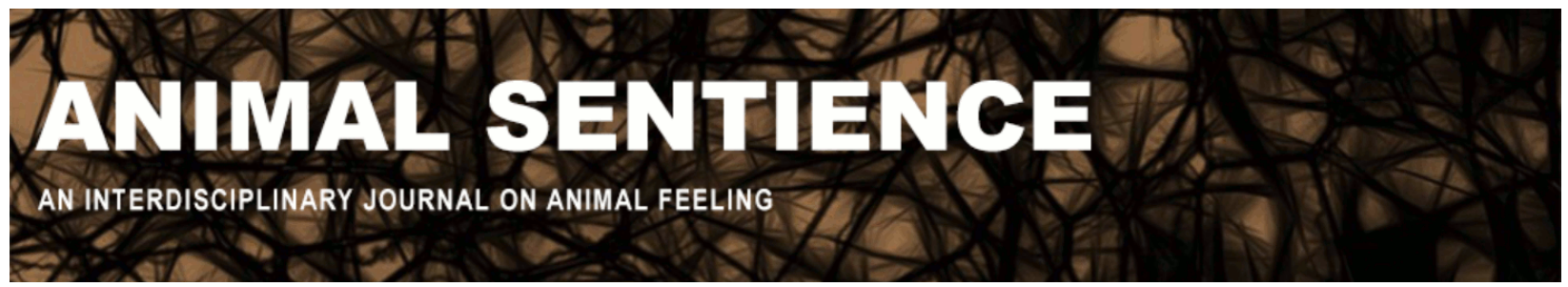

Snijders, Lysanne (2020) Ecological and evolutionary dynamics of elephant rewilding. Animal Sentience 28(6)

DOI: $10.51291 / 2377-7478.1562$

Date of submission: 2020-02-28

Date of acceptance: 2020-03-03

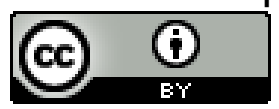

This article has appeared in the journal Animal

Sentience, a peer-reviewed journal on animal

cognition and feeling. It has been made open access,

free for all, by WellBeing International and deposited

in the WBI Studies Repository. For more information,

please contact

wbisr-info@wellbeingintl.org.

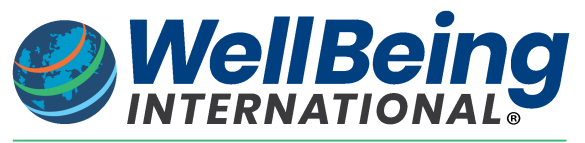

SOLUTIONS FOR PEOPLE, ANIMALS AND ENVIRONMENT 


\title{
Ecological and evolutionary dynamics of elephant rewilding
}

Commentary on Baker \& Winkler on Elephant Rewilding

\author{
Lysanne Snijders \\ Behavioural Ecology Group \\ Wageningen University \& Research
}

\begin{abstract}
Baker \& Winkler make a thought-provoking contribution to the discussion of what role captive animals could play in nature conservation and how we could get there through rewilding. There certainly is potential for captive Asian elephants, Elephas maximus, to become targets of conservation efforts, but there are also many questions: (1) How much do (behavioral) traits of captive-origin animals differ from their free conspecifics? (2) What predicts the likelihood and strength of social reintegration of captive animals into free populations? (3) How much of an Asian elephant's functional role in the environment can captive animals still fulfill and how may this influence the evolutionary dynamics of Asian elephant populations? These questions are challenging, but also an opportunity to gain crucial knowledge and insight into the elephant's ecological role, as well as our own.
\end{abstract}

Lysanne Snijders, behavioral ecologist, does research on animal social behavior and personality, including the potential implications of behavioral variation for conservation. Her study taxa (so far) comprise birds, fish and mammals. Website

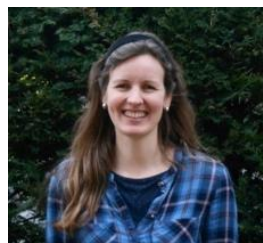

"Wildness concerns the degree to which individuals exists autonomously in evolutionary and ecologically functioning populations where genetic and phenotypic diversity enables natural selection to produce adaptation." (Child et al., 2019)

Through defining wildness, Child et al.'s quote above nicely puts into words what is at the core of nature conservation: conserving and facilitating the potential for natural adaptation of populations, species and ecosystems. At the same time, it reveals the subjectivity that challenges conservation. Many of the concepts mentioned are open to interpretation. When do we define an individual animal as autonomous (e.g. Thompson, 2017)? How do we determine and measure the ecological functions of a population (e.g. Davidson, 2019)? What do we count as valuable units of diversity (e.g. Stronen \& Paquet, 2013)? And does natural selection include selection driven by anthropogenic pressures (e.g. Child et al., 2019)? Whether captive Asian elephants can and should become targets of conservation actions, as Baker \& Winkler (2020) (B\&W) advocate, thus partly depends on one's interpretation of what it means to do conservation.

1. Do captive and free elephants differ in some significant, scientifically measurable way? B\&W suggest that captive Asian elephants are not 'domesticated' and therefore do not significantly differ from free-living elephants. Hence, captive elephants are entitled to conservation concerns. But what do we really know about the similarities and differences of captive versus free Asian elephants? Obviously, there are many similarities, but being raised in a different abiotic, biotic and social environment is bound to leave its marks. For example, 
semi-captive female Asian elephants born in stressful periods (e.g. in times of heavy workloads and the start of the monsoon) exhibit faster reproductive senescence and experience significantly reduced lifetime reproductive success (Mumby et al., 2015).

A number of (behavioral) traits may differ in response to captivity, such as social behavior, spatial behavior, cognition, communication skills, anti-predator behavior, parental care and personality, to name just a few. From a conservation perspective, such differences should only be an issue when they are fixed (i.e. do not converge after rehabilitation and rewilding) and are hampering the elephants in their ecological and evolutionary functioning. The only way to find out whether this is the case is to actually rewild the elephants, using an adaptive management framework, and systematically observe and measure what happens (Miththapala, 2009). As B\&W note, this is a topic ripe for research. The rewilding of captive Asian elephants offers a vital learning opportunity for elephant conservation as well as for ecological, evolutionary and behavioral research.

2. What about social functionality and social integration? It will be essential to ensure that the captive Asian elephant does not become a biological entity distinct from the free Asian elephant. In this regard, I must disagree with Suter (2020), who argues for elephant conservation through welfare-improved elephant camps (if this indeed excludes social integration into free populations). The social relationships of wildlife populations modulate their ecological and evolutionary roles (Kurvers et al., 2014) and can play a key role in their conservation (Snijders et al., 2017). For example, in African elephants, Loxodonta africana, the number of conspecifics a translocated individual associates with correlates positively with their body condition (Pinter-Wollman et al., 2009), and population-level resilience to poaching in African elephants is driven by daughters taking over the social roles of their mothers (Goldenberg et al., 2016). The incorporation of social functionality in translocation protocols, especially those of elephants, is hence strongly recommended (Goldenberg et al., 2019).

$B \& W$ report that previously released captive Asian elephants appear to have adapted well, forming social groups similar to those in the wild (Thitaram et al., 2015) and that similar outcomes have been observed for released orphans in Sri Lanka (Miththapala, 2009). Yet, looking at these reports more closely paints a somewhat more ambiguous picture, with released elephants showing very little relatedness, an aspect that could have an important impact on their social dynamics (Goldenberg et al., 2019; Harvey et al., 2018) and evidence from Sri Lanka of some (groups) of elephants not integrating at all. Again, this offers an important learning opportunity. How long do elephants need to integrate socially (PinterWollman et al., 2009), both amongst themselves and free conspecifics? What factors, such as the social structure of the herd, the personality of the released elephant, the presence of trauma, may predict why some elephants integrate and others do not (Miththapala, 2009)?

3. What ecological roles can captive elephants (still) play? Setting aside, for a moment, the discussion of whether continued human-elephant relationships are in the best interest of the elephants (see the commentaries of Kopnina (2020), Pauketat (2020) and Suter (2020) for varying views), these relationships are likely to have an impact on the degree of social integration that is possible. As Lainé (2020) notes, it would accordingly be good to get a more detailed image of the daily relationship between the Karen mahouts and the elephants, both now and as envisioned for future generations. The impact of human-elephant relationships on the ability to form evolutionarily relevant elephant-elephant relationships might prove smaller 
than we predict, given that social structures in free elephants are, to some degree, variable and flexible (de Silva \& Wittemyer, 2012). But this would need to be studied.

Elephants are clear ecosystem engineers - for example, through their role as seed dispersers (Campos-Arceiz \& Blake, 2011). The behaviors and social structures that strongly modulate an elephant's ecological and evolutionary roles may, however, be fundamentally restricted in a 'guardianship' system. Spatial behavior, and specifically natal dispersal, is an obvious example. Restrictions in free elephant-typical behaviors will not only affect their capacity to influence ecosystems but also their contribution to genetic diversity (Ahlering et al., 2011). The key question may therefore not be whether they will be restricted, but rather how much? Given the current levels of habitat fragmentation and destruction, one can admittedly pose the exact same questions for (certain populations of) free Asian elephants (Choudhury et al., 2008).

\section{References}

Ahlering, M. A., Hedges, S., Johnson, A., Tyson, M., Schuttler, S. G., \& Eggert, L. S. (2011). Genetic diversity, social structure, and conservation value of the elephants of the Nakai Plateau, Lao PDR, based on non-invasive sampling. Conservation Genetics, 12(2), 413422.

Baker, L., \& Winkler, R. (2020). Asian elephant rescue, rehabilitation and rewilding. Animal Sentience 28(1).

Campos-Arceiz, A., \& Blake, S. (2011). Megagardeners of the forest - the role of elephants in seed dispersal. Acta Oecologica, 37(6), 542-553.

Child, M. F., Selier, S. A. J., Radloff, F. G. T., Taylor, W. A., Hoffmann, M., Nel, L., Power, R. J., Birss, C., Okes, N. C., Peel, M. J., Mallon, D., \& Davies-Mostert, H. (2019). A framework to measure the wildness of managed large vertebrate populations. Conservation Biology, 33(5), 1106-1119.

Choudhury, A., Lahiri Choudhury, D. K., Duckworth, J. W., Easa, P. S., Johnsingh, A. J. T., Fernando, P., Hedges, S., Gunawardena, M., Kurt, F., Karanth, U., Lister, A., Menon, V., Riddle, H., Rübel, A., \& Wikramanayake, E. (2008). Asian Elephant: Elephas maximus. International Union for Conservation of Nature, Asian Elephant Specialist Group.

Davidson, J. (2019). 'Functionally extinct' koalas have now lost $80 \%$ of habitat following recent fires, experts say. EcoWatch.

de Silva, S., \& Wittemyer, G. (2012). A comparison of social organization in Asian Elephants and African Savannah Elephants. International Journal of Primatology, 33(5), 1125-1141.

Goldenberg, S. Z., Douglas-Hamilton, I., \& Wittemyer, G. (2016). Vertical transmission of social roles drives resilience to poaching in elephant networks. Current Biology, 26(1), 75-79.

Goldenberg, S. Z., Owen, M. A., Brown, J. L., Wittemyer, G., Oo, Z. M., \& Leimgruber, P. (2019). Increasing conservation translocation success by building social functionality in released populations. Global Ecology and Conservation, e00604.

Harvey, N. D., Daly, C., Clark, N., Ransford, E., Wallace, S., \& Yon, L. (2018). Social interactions in two groups of zoo-housed adult female Asian elephants (Elephas maximus) that differ in relatedness. Animals, 8(8), 132.

Kopnina, H. (2020). Of elephants and men. Animal Sentience 28(2). 
Kurvers, R. H., Krause, J., Croft, D. P., Wilson, A. D., \& Wolf, M. (2014). The evolutionary and ecological consequences of animal social networks: Emerging issues. Trends in Ecology \& Evolution, 29(6), 326-335.

Lainé, N. (2020). Anthropology for conservation. Animal Sentience 28(5).

Miththapala, S. (2009). The Uda Walawe Elephant Transit Home - another opportunity missed? Gajah, 30, 24-28.

Mumby, H. S., Mar, K. U., Hayward, A. D., Htut, W., Htut-Aung, Y., \& Lummaa, V. (2015). Elephants born in the high stress season have faster reproductive ageing. Scientific Reports, 5(1), 1-11.

Pauketat, J. V. T. (2020). A psychological perspective on elephant rewilding. Animal Sentience 28(4).

Pinter-Wollman, N., Isbell, L. A., \& Hart, L. A. (2009). The relationship between social behaviour and habitat familiarity in African elephants (Loxodonta africana). Proceedings of the Royal Society B: Biological Sciences, 276(1659), 1009-1014.

Snijders, L., Blumstein, D. T., Stanley, C. R., \& Franks, D. W. (2017). Animal social network theory can help wildlife conservation. Trends in Ecology \& Evolution, 32(8), 567-577.

Stronen, A. V., \& Paquet, P. C. (2013). Perspectives on the conservation of wild hybrids. Biological Conservation, 167, 390-395.

Suter, I. (2020). Rewilding or reviewing: Conservation and the elephant-based tourism industry. Animal Sentience 28(3).

Thitaram, C., Dejchaisri, S., Somgird, C., Angkawanish, T., Brown, J., Phumphuay, R., Chomdech, S., \& Kangwanpong, D. (2015). Social group formation and genetic relatedness in reintroduced Asian elephants (Elephas maximus) in Thailand. Applied Animal Behaviour Science, 172, 52-57.

Thompson, S. (2019). Supporting ape rights: Finding the right fit between science and the law. ASEBL Journal 14(1). 


\section{Call for Papers}

\section{Special Issue of the Lournal of Consciousness Studies}

Plant Sentience: Theoretical and Empirical Issues

Guest Editors: Vicente Raja (Rotman Institute of Philosophy, Western University) Miguel Segundo-Ortin (School of Liberal Arts, University of Wollongong)

In this special issue, we address the issue of plant sentience/consciousness from different disciplines that combine both theoretical and empirical perspectives. Some of the questions to be addressed in the special issue include the following:

- Plants exhibit interesting behaviors; does this entail that they are conscious to some extent?

- What are the requirements for a living organism to be conscious? Do plants meet these requirements?

- What does the possibility of plant sentience/consciousness entail for the study of the evolution of consciousness?

- Is it just a categorical mistake to attribute consciousness to plants?

- Can we talk about different levels or degrees of consciousness?

\section{How to submit?}

\section{Deadline: June $\mathbf{1}^{\text {st }}, \mathbf{2 0 2 0}$}

Please submit your papers (max. 9000 words including footnotes, references, abstract, etc.) to vgalian@uwo.ca with subject "Paper Special Issue JCS".

For more information, including bibliography and more detailed descriptions of the topics and questions to be addressed in the papers submitted to the special issue, please contact the guest editors at vgalian@uwo.ca (Vicente) or mso693@uowmail.edu.au (Miguel). 